\title{
Cyclopiazonic Acid Is a Pathogenicity Factor for Aspergillus flavus and a Promising Target for Screening Germplasm for Ear Rot Resistance
}

\author{
Subbaiah C. Chalivendra, ${ }^{1}$ Catherine DeRobertis, ${ }^{1}$ Perng-Kuang Chang, ${ }^{2}$ and Kenneth E. Damann ${ }^{1}$ \\ ${ }^{1}$ Louisiana State University Ag Center, Baton Rouge, LA 70803, U.S.A.; and ${ }^{2}$ USDA-Southern Region Research Center, New \\ Orleans, LA 70124, U.S.A.
}

Accepted 1 March 2017.

\begin{abstract}
Aspergillus flavus, an opportunistic pathogen, contaminates maize and other key crops with carcinogenic aflatoxins (AFs). Besides AFs, A. flavus makes many more secondary metabolites (SMs) whose toxicity in insects or vertebrates has been studied. However, the role of SMs in the invasion of plant hosts by A. flavus remains to be investigated. Cyclopiazonic acid (CPA), a neurotoxic SM made by A. flavus, is a nanomolar inhibitor of endoplasmic reticulum calcium ATPases (ECAs) and a potent inducer of cell death in plants. We hypothesized that CPA, by virtue of its cytotoxicity, may serve as a key pathogenicity factor that kills plant cells and supports the saprophytic life style of the fungus while compromising the host defense response. This proposal was tested by two complementary approaches. A comparison of CPA levels among A. flavus isolates indicated that CPA may be a determinant of niche adaptation, i.e., isolates that colonize maize make more CPA than those restricted only to the soil. Further, mutants in the CPA biosynthetic pathway are less virulent in causing ear rot than their wild-type parent in field inoculation assays. Additionally, genes encoding ECAs are expressed in developing maize seeds and are induced by A. flavus infection. Building on these results, we developed a seedling assay in which maize roots were exposed to CPA, and cell death was measured as Evans Blue uptake. Among >40 maize inbreds screened for CPA tolerance, inbreds with proven susceptibility to ear rot were also highly CPA sensitive. The publicly available data on resistance to silk colonization or AF contamination for many of the lines was also broadly correlated with their CPA sensitivity. In summary, our studies show that i) CPA serves as a key pathogenicity factor that enables the saprophytic life style of A. flavus and ii) maize inbreds are diverse in their tolerance to CPA. Taking advantage of this natural variation, we are currently pursuing both genome-wide and candidate gene approaches to identify novel components of maize resistance to Aspergillus ear rot.
\end{abstract}

Aflatoxins (AFs), the secondary metabolites (SMs) of Aspergillus flavus, are the most potent naturally occurring

Corresponding author: S. C. Chalivendra;

E-mail: schalivendra@agcenter.lsu.edu

*The $\boldsymbol{e}$-Xtra logo stands for "electronic extra" and indicates that three supplementary figures and two supplementary tables are published online.

This article is in the public domain and not copyrightable. It may be freely reprinted with customary crediting of the source. The American Phytopathological Society, 2017. carcinogens and a serious threat to our food safety and agricultural productivity. Even disregarding the indirect costs, the direct revenue loss due to $\mathrm{AF}$ contamination in maize alone is at least \$200 million per year in the United States (AMCOE 2013). AF contamination is of particular concern in countries with less stringent regulation of food safety. Owing to its durability and the low cost to the grower, the incorporation of preharvest resistance in elite local cultivars is the best strategy for controlling AF. Of several crops contaminated by AF, maize (Zea mays L.) is of primary interest, not only due to its many commercial uses, but also, its high yield and great adaptability as a food, feed, and forage crop. It is also a powerful genetic model with its remarkable diversity and a variety of experimental resources. However, nearly three decades of concerted breeding efforts have not yielded a maize line completely resistant to $\mathrm{AF}$ contamination. This is because current resistance screens based mainly on AF measurements are fraught by a huge seasonal and plant-to-plant variability (Warburton and Williams 2014). Although manual inoculations can reduce some variability, the most effective manipulations (e.g., pin-bar inoculation) are labor intensive. Besides, highly invasive inoculation methods may allow the fungus to bypass host resistance mechanisms manifested under natural infection. On the other hand, a screen that targets the ability of the fungus to kill and gain entry into living tissues may offer a robust strategy and reveal a key component of host resistance.

Similar to many Aspergillus spp., A. flavus lives as a freeliving saprophyte in the soil, mostly on the decaying vegetation. When presented with a nutrient-rich host (e.g., developing kernels), the opportunistic pathogen turns, transiently, into a parasite, killing and macerating unwounded and wounded host tissues to switch back into a saprophyte (Payne 1998; Reverberi et al. 2013; St. Leger et al. 2000). Necrotrophic pathogens use one or more SMs in establishing a parasitic interaction with the host. Evidence for the role of SMs in A. flavus virulence comes from pleiotropic regulatory mutants. LaeA and VeA, components of the nuclear localized Velvet complex, regulate morphogenesis as well as the biosynthesis of SMs in several Aspergillus spp. (Bok and Keller 2016; Hong et al. 2015). In A. flavus, loss of LaeA leads to a loss in AF and cyclopiazonic acid (CPA) and several anti-insectan compounds such as piperazines, aspergillic acid, paspaline, aflatrem, and aflavinine (Bok and Keller 2016; Li et al. 2002; TePaske et al. 1989, 1992). Notably, an overexpression of laeA induces the production of CPA in A. fumisynnematus, which does not normally produce CPA (Hong et al. 2015). Similar to LaeA, $\mathrm{VeA}$ is required for the synthesis of $\mathrm{CPA}, \mathrm{AF}$, and aflatrem in A. flavus (Duran et al. 2007). Deletion mutants in either veA or laeA are severely defective in colonizing maize and peanut seeds as well as developing cotton bolls (Amaike and Keller 2009; 
Duran et al. 2009; Kale et al. 2008), indicating the requirement of one or more SMs for infection. Although several SMs are regulated by the Velvet complex, AFs and CPA are made in the actively growing and sporulating fungus that serves as the airborne inoculum. Only AF and CPA gene clusters are fully induced during A. flavus transition from a saprophyte into a parasite (Dolezal et al. 2013; Reverberi et al. 2013). The anti-insectan compounds are produced predominantly or exclusively in sclerotia that remain in the soil as resting propagules (Wicklow et al. 1994), and gene clusters relevant to these SMs are silent during A. flavus infection of living maize seeds (Dolezal et al. 2013; Reverberi et al. 2013).

AF can retard plant growth (Dashek et al. 1981) but there is no evidence for its involvement in pathogenicity. In fact, strains or mutants that make very little or no AF are more vigorous and infectious on maize (Ehrlich et al. 2011; Hruska et al. 2014; Yang et al. 2016). On the other hand, there is a strong rationale to implicate CPA in the virulence of A. flavus. CPA, an indole tetramic acid SM secreted by A. flavus (Benkhemmar et al. 1985), is a specific inhibitor of endoplasmic reticulum (ER) or ER calcium ATPases (ECAs) in many taxa, including plants (Goeger et al. 1988; Johnson et al. 2009; Liang and Sze 1998). Being low affinity $\mathrm{Ca}^{2+}$ transporters localized on endomembranes, ECAs pump out cytosolic $\mathrm{Ca}^{2+}$ into cellular compartments (i.e., ER and vacuole) only when it reaches supra-optimal concentrations. Inhibition of ECAs by CPA leads to an unmitigated rise in cytosolic $\mathrm{Ca}^{2+}$ and, consequently, induces plant cell death (Berridge 1993; Ihara-Ohori et al. 2007; Ishikawa et al. 2011; Zuppini et al. 2004). Biotic and abiotic stress-induced $\mathrm{Ca}^{2+}$ rise is modulated by the activity of ECAs, such that the adaptive signaling is allowed to proceed while a lethal rise in $\mathrm{Ca}^{2+}$ is quenched (Nemchinov et al. 2008; Qudeimat et al. 2008). In developing maize seeds, ECA transcripts were two- to sixfold more abundant in the resistant line than in the line susceptible to Fusarium verticilloides ear rot (Lanubile et al. 2014), indicating a role for ECAs in protecting against cellular damage caused by pathogens. In tobacco, silencing a specific eca gene accelerated the programmed cell death (PCD) induced by fungal elicitors (Zhu et al. 2010). Since CPA binds directly and inactivates all ECA proteins in the host cell, it can inflict more widespread cellular damage by leaking ER $\mathrm{Ca}^{2+}$ into the cytosol than the targeted silencing of a specific eca gene. The CPA-insensitive plasma membrane $\mathrm{Ca}^{2+}$ ATPases can restore cytosolic $\mathrm{Ca}^{2+}$ homeostasis but they cannot refill the $\mathrm{ER} \mathrm{Ca}^{2+}$ store, due to their intracellular location. The loss of ER $\mathrm{Ca}^{2+}$ can be damaging to the cell from unfolded protein response (Iwano et al. 2009; Li et al. 2008). In genus Lepidium, even a 2-h treatment of primary roots with $20 \mu \mathrm{M}$ CPA led to the aggregation of ER, hypertrophy of Golgi vesicles, and a loss of gravitropism (Busch and Sievers et al. 1993). The proposed interaction of ECAs with the Bax inhibitor, a PCD-suppressor protein also localized to the ER, further explains the role of $\mathrm{Ca}^{2+}$ homeostasis in pathogen-induced cell death (Ihara-Ohori et al. 2007; Ishikawa et al. 2011). Overexpression of Arabidopsis Bax inhibitor-1 (AtBI-1) decreased the hypersensitive cell death induced by Magnaporthe spp. in rice (Matsumura et al. 2003) or CPAinduced cytosolic $\mathrm{Ca}^{2+}$ rise and cell death in tobacco (Ihara-Ohori et al. 2007). Conversely, atbi-1 mutants are overly sensitive to CPA-induced cell death (Ihara-Ohori et al. 2007). The anti-PCD activity of AtBI-1 is dependent on functional $\mathrm{Ca}^{2+}$ pumps in yeast. Since CPA perturbs the homeostasis of a versatile signaling molecule (i.e., $\mathrm{Ca}^{2+}$ ), it can compromise the host defense response even at sublethal concentrations and act as a potent weapon for A. flavus in invading living plant tissues.

There is also correlative evidence to implicate CPA in the virulence of $A$. flavus. The field infectivity of maize by two closely related species, A. flavus and A. parasiticus, correlates with their ability to make CPA. A. flavus extensively infects maize, while the latter poorly colonizes maize and lives predominantly as a soil saprobe (Horn et al. 1995). While A. flavus makes CPA, it is capable of making mostly AF $B_{1}$ but neither $\mathrm{G}_{1}$ nor $\mathrm{G}_{2}$. On the other hand, A. parasiticus lacks a functional CPA biosynthesis gene cluster (Chang et al. 2009b) but has a more elaborate AF synthesis machinery to make $\mathrm{B}$ and $\mathrm{G}$ type AFs. Unlike A. flavus, A. parasiticus does not lose the ability to produce AF in culture over time and rarely becomes atoxigenic even in nature (Lillehoj 1987), which may be important for its adaptation to the soil niche. Consistent with this notion, crop commodities are predominantly contaminated by B type AFs and rarely by $\mathrm{G}$ type toxins (Lillehoj 1987). Even in A. flavus, isolates that mainly or only colonize the soil produce more AF than those that can infect maize (Sweany et al. 2011). In this study, we probed further this correlation between CPA production and niche adaptation among A. flavus isolates as well as CPA biosynthesis mutants and demonstrated a role for CPA in A. flavus virulence. We also developed a laboratory assay to measure CPA tolerance in maize germplasm and are currently analyzing the genomic sequences associated with the trait. CPA tolerance can be due to any one or more of these mechanisms: i) an active CPA degradation/sequestration pathway, ii) a host factor that suppresses CPA production, and iii) CPA-insensitivity because of differences in either ECA abundance, a CPAresistant ECA isoform, or both. Since the molecular nature of the first two strategies is not known, we are taking a genomewide association approach, using the maize nested-association mapping (NAM) panel, initially using the NAM founder lines. As ECAs present an obvious and immediate choice for the third strategy, we have analyzed eca genes in a candidate gene approach.

\section{RESULTS}

\section{A. flavus kernel isolates make more CPA than soil isolates.}

Since CPA has the attributes to be a candidate virulence factor, we compared CPA contents of A. flavus isolates with distinct niche preference. These isolates form a part of populations colonizing 11 maize fields across Louisiana (Sweany et al. 2011). Within these collections, isolates belonging to only six of 16 vegetative compatibility groups (VCGs) were recovered from kernel samples, while the rest were exclusively soil-living. Subsequent field inoculation tests with these isolates indicated that only certain A. flavus genotypes are pathogenic to maize (Damann 2015). We selected six each of kernel and soil isolates for CPA analysis. Kernel isolates had $>10$-fold more CPA than soil isolates, on average, and the differences were statistically significant (Fig. 1). Each of the kernel isolates had $>50 \mu \mathrm{g}$ of CPA per milliter of culture with the average above $200 \mu \mathrm{g}$ of CPA per milliliter, while half of the soil isolates made none and the other half made low amounts of the compound. CPA levels in kernel isolates are three to 30 -fold equivalent to concentrations proven to be cytotoxic in three different plant species (Ihara-Ohori et al. 2007; Ishikawa et al. 2011; Zuppini et al. 2004). In our thin-layer chromatography (TLC) analyses, we used A. parasiticus as a negative control. A. parasiticus, known for its poor infectivity on maize, did not produce any CPA (data not shown), which is consistent with previous reports (Dorner et al. 1984; Klich and Pitt 1988). This correlation between CPA production and the ability to infect maize is found to be valid among individual A. flavus isolates adapted to either kernel or soil colonization.

\section{Knockouts in CPA biosynthesis are less infectious in field inoculation tests.}

The role of CPA as a virulence factor was further assessed by comparing CPA-null mutants with their isogenic parent in 
the field. In A. flavus, CPA is synthesized using a short pathway driven by three enzymes, namely, polyketide synthasenonribosomal peptide synthetase, $O$-dimethylallyl tryptophan synthase, and monoamine oxidase (Chang et al. 2009b; Liu and Walsh 2009). In previous work, Chang et al. (2009b) generated insertional mutants in genes encoding each of the three enzymes. CPA was not detectable in any of the mutants (Chang et al. 2009b) (Fig. 2, inset), while AF synthesis was unaffected (Supplementary Fig. S1). In summer 2015, we tested the field

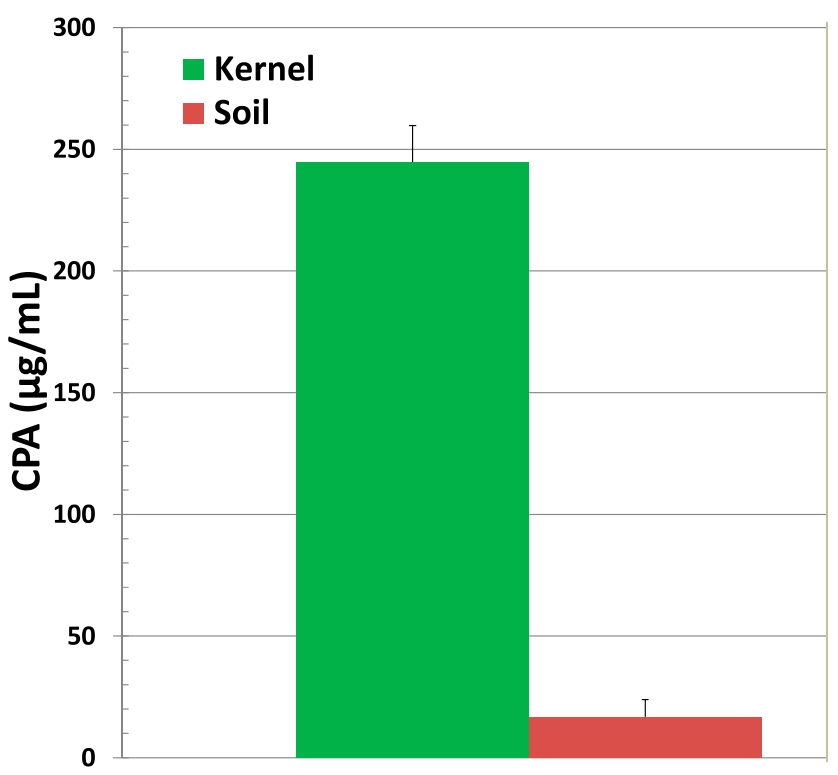

Fig. 1. Mean (+standard error) cyclopiazonic acid (CPA) levels in six kerne and six soil isolates. CPA content in kernel and soil isolates was extracted and analyzed as described by Chang et al. (2009b). The plate was scanned (using a Bio-Rad ChemiDoc XRS+ System with Image Lab) and spot areas and intensities were quantified. CPA content was estimated from a standard curve generated from 10 to $50 \mu \mathrm{g}$ of CPA loaded on the same plate. Averages are significantly different at a 99\% confidence level ( $t$ test). infectivity of pks-nrps and maoA knockout strains and their isogenic parent, CA14N1, by conidial sprays on yellowing silks. As shown in Figure 2, the CPA-deficient strains were less aggressive in contaminating maize kernels with AF. Visual symptoms of fungal contamination were also more prominent in ears infected with the wild-type parent. In 2016, all three mutants were compared with the wild type, using a seed corn line. Consistently, CPA mutants were less infective than the isogenic parent (Supplementary Fig. S2), although A. flavus infectivity across all our field experiments was much lower than in 2015 .

Four genes encode ECAs, the targets of CPA, in maize.

Since CPA is a specific and strong inhibitor of ECAs, it is likely that CPA tolerance is encoded in the maize genome and governed by altered expression of $e c a$ genes or affinity of ECAs to the inhibitor. Additional tolerance mechanisms targeting CPA biosynthesis in the fungus or CPA transport, sequestration, or degradation alone or in combination in plant cells may exist and our genome-wide analysis studies (GWAS) may reveal their molecular nature. Therefore, we identified and annotated maize genes encoding ECAs in the Maize Genetics and Genomics database (maizeGDB). ZmCAP1 is the first and only characterized ECA in maize (Subbaiah and Sachs 2000). To conform to the plant $\mathrm{Ca}^{2+}$ pump nomenclature (and also to avoid the repeated use of an anagram of CPA in this manuscript), we are adding the synonym ECA1 to the CAP1 protein. The capl (synonym ecal) gene is located on the long arm of Chr8 (gene model in B73 reference genome version AGPv3: GRMZM2G056014 and, in the newly released version AGPv4: Zm00001d011013) (Fig. 3A) and the gene coordinates map to bin 8.05, which colocalizes to a long AF resistance quantitative trait locus (QTL) spanning bins 8.02 to 8.05 with resistance to different components of A. flavus resistance (Mideros et al. 2014; Willcox et al. 2013). The QTL in bin 8.05 is specifically associated with silk resistance to A. flavus sporulation (Mideros et al. 2014). Genome sequencing has revealed the presence of three additional eca-like sequences in maize (Fig. 3A), one on the long arm of Chr9 (gene model in AGPv3: GRMZM2G162426 and in AGPv4: Zm00001d047769; cap3 synonym eca3) and two on Chr1, one on the small arm (a

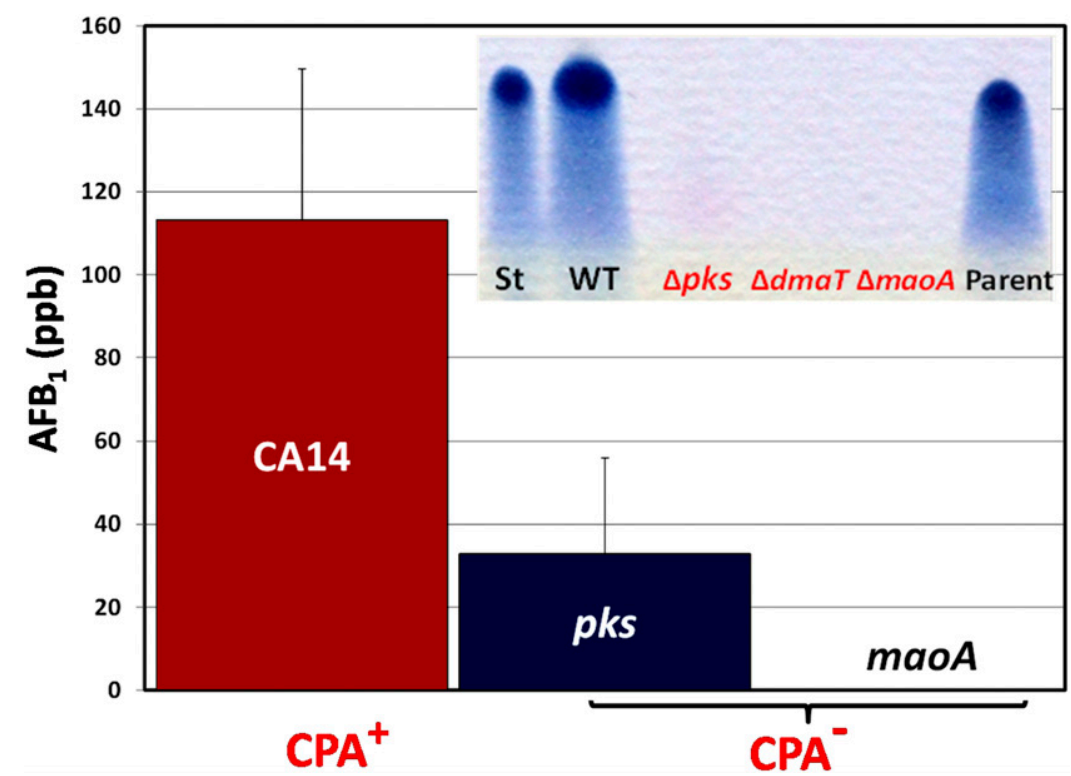

Fig. 2. Cyclopiazonic acid (CPA) knockouts of Aspergillus flavus are less infective in maize. Insertional mutants in any of the three CPA biosynthetic genes make no CPA, as shown by thin-layer chromatography (inset), but produce the same levels of aflatoxins (AF) as the parent strain in synthetic media. The wild type and two of the mutant strains were tested for their infectivity in maize by conidial sprays on silks. Ears were harvested at maturity and AF levels were estimated by high-pressure liquid chromatography. Visual growth of fungus was much lower on kernels infected by the two CPA-deficient strains. 
split gene with two gene models in AGPv3: GRMZM2G428096 and GRMZM2G141704, separated by a spacer of 154 bases and merged into a single gene model Zm00001d028687 in AGPv4; cap2 synonym eca2) and the other on the long arm (gene model in AGPv3: AC233878.1_FG004 and in AGPv4: Zm00001d033886; cap4 synonym eca4). eca2 localizes to bin 1.03, which has a QTL
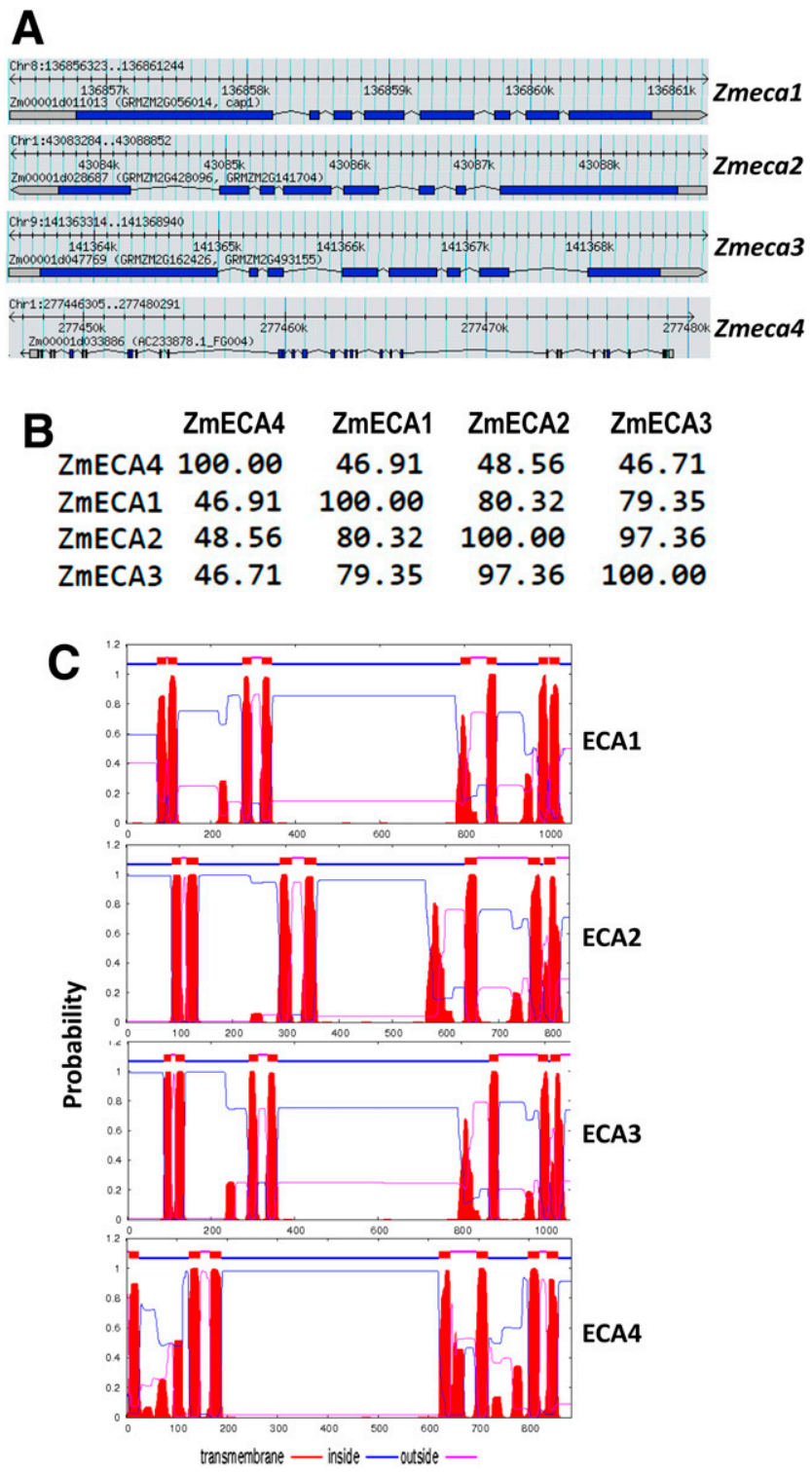

Fig. 3. A, Maize genome tracks showing the locations of ecal (synonym cap1) and its paralogs. The exons are indicated by dark-shaded rectangles and introns by black lines. The two gene models associated with eca2 (Chr1: 42855656 to 42857040, GRMZM2G428096; Chr1: 42849862 to 42855504 , GRMZM2G141704) in AGPv3 assembly appear to be a potential assembly problem (they have been merged into a single gene model in the AGPv4 released in December 2016). For example, transcripts corresponding to both gene models are detected in the published RNA-Seq data (Sekhon et al. 2012; Stelpflug et al. 2016), but peptides corresponding only to GRMZM2G428096 were detected in proteome studies (Walley et al. 2013 2016). B, Similarity matrix of endoplasmic reticulum calcium ATPase (ECA) protein sequence comparison. All four ECA protein sequences were aligned using the CLUSTALW program in MUSCLE (Edgar 2004) and the similarity score between each pair is presented. ECA2 and ECA 3 are the closest pair, whereas ECA1 and ECA4 are the farthest among the four maize ECA proteins. C, Predicted transmembrane (TM) domains of ECA proteins. TMHMM 2.0 (Möller et al. 2001) was used to predict TM regions of ECA proteins. Maize ECAs have ten TM domains similar to canonical ECAs across species, except in ECA4, which has additional TM domains, as predicted by the program. associated with resistance to A. flavus sporulation in developing kernels and eca4 to a QTL in bin 1.10 for latent period of in vitro colonization of silk (Mideros et al. 2014). Only two A. flavusrelated QTL have been reported so far, one in bin 9.04, related to seed AF levels (Warburton et al. 2015), and the second in bin 9.07, associated with resistance to sporulation on kernels (Mideros et al. 2014). Neither colocalizes with eca3, which maps to bin 9.06. ecal, $e c a 2$, and eca3 are similar in their exon-intron structure, whereas eca4 is highly divergent in its organization, with multiple introns (>20) and short exons, indicating a different orthology of eca4 from the other three genes. This divergence is also reflected by the primary amino acid sequences (Fig. 3B) and predicted secondary structures of the encoded proteins (Fig. 3C).

A search for conserved cis-regulatory elements in maize eca gene promoters showed the presence of many motifs known to be involved in pathogen-inducible expression, such as methyl jasmonate-inducible and fungal elicitor-responsive elements (Table 1). In addition, conserved motifs that confer endosperm expression, such as Opaque2, Skn1, and GCN4, as well as sequences involved in anoxia responsiveness (ARE and GC motif, which may also confer seed or endosperm expression) are present in all four eca promoters. ECA1 transcripts are, in fact, shown to be induced only under anoxia, among other abiotic stresses, and the corresponding cDNA clone was isolated from a library made from maize seedling roots submerged for $6 \mathrm{~h}$ (Subbaiah and Sachs 2000). Developing seeds and subterranean roots being chronically hypoxic may need highly active ECAs to regulate their cytosolic $\mathrm{Ca}^{2+}$ and, consequently, may be more prone to CPA cytotoxicity.

\section{eca genes are expressed in kernels and induced} by $A$. flavus infection.

We mined a publicly available maize transcriptome and proteome database, maizeGDB (Sekhon et al. 2011; Stelpflug et al. 2016; Walley et al. 2016) and found that all four genes are expressed with varying magnitude in developing seeds and prepollinated cobs including silks. Transcripts for all four genes except for ecal/capl are maximally expressed in seed tissues (the embryo, the endosperm, and the pericarp) among all 69 juvenile and adult maize tissues tested (Fig. 4A). However, ECA1 protein is the most abundant in the endosperm among all 33 tissues analyzed for proteome (Fig. 4B). ECA2A and ECA3 proteins are also expressed in seed tissues. Peptides covering CAP4 and the carboxy terminal half of CAP2 (gene model: GRMZM2G141704) are not detected in any of the sampled maize tissues, including seeds.

We tested the inducibility of ECAs by A. flavus infection. In developing maize seeds, ECA transcripts were induced by all A. flavus isolates tested, but the extent of induction was greater in G14- and G25-infected seeds and correlated with their superior virulence (Fig. 5A and B). Further, CPA accumulation was greater in kernels infected by these two virulent isolates (approximately $350 \mu \mathrm{g}$ per gram of kernel powder dry mass) (Fig. 5C). CPA level was also greater in G10 than in G11, thus matching with its higher biomass in the kernels, although the ECA transcript induction was not different between these two isolates. Taken together, these data support the role of CPA as a key pathogenicity factor. On the other hand, AF levels of these isolates, either in infected kernels or in culture media, showed no correlation with the fungal biomass (data not shown) (Geiser et al. 2000). We also monitored the changes in ECA transcript levels in CPA-treated roots in three maize inbreds differing in their resistance to AF accumulation (i.e., B97, IL14H, and Tzi8) (data not shown). There was only a twofold induction of ECA1 in all three lines. ECA3 transcripts were also induced by twofold only in IL14H and Tzi8 but repressed by fivefold in B97, indicating that maize inbreds differ in their response to CPA exposure. 
CPA sensitivity is highly diverse among maize inbreds and correlated to silk colonization and AF contamination.

Prompted by the evidence for CPA involvement in A. flavus pathogenicity, we developed a seedling assay in which maize roots are exposed to CPA for $18 \mathrm{~h}$ and are stained for cell death using Evans Blue (Fig. 6). The root sensitivity to CPA is consistent with the high abundance of ECA transcripts and proteins in root tissues (Fig. 4A and B). CPA-induced cell death was quantified by the spectrophotometric measurement of Evans Blue extracted from roots, as described previously (Chandran et al. 2008; Yamamoto et al. 2001). Using the quantitative assay for CPA sensitivity, we screened maize inbreds that include popular lines field tested often for their AF resistance as well as those that constitute the maize NAM panel. Inbreds known for their susceptibility (e.g., B73 and Va35) or resistance (e.g., $\mathrm{Mp717}$ ) to ear rot were also highly sensitive or tolerant to CPA (Campbell and White 1995; Henry et al. 2009) (Figs. 6 and 7A). Maize inbreds showed a great diversity for the trait and a strong uniformity within a genotype (Figs. 6 and 7A). The high broadsense heritability value $\left(\mathrm{H}^{2}=0.75\right)$ estimated from the data indicates that CPA sensitivity is a reliable selection parameter for screening maize germplasm. In the absence of insect damage, silk is the main, and probably the only, infection route for Aspergillus ear rot. It is noteworthy that the root CPA tolerance shows a modest but significant correlation (Pearson $r=0.67$; $P=0.004)$ to silk resistance against A. flavus colonization in field inoculation studies (Mideros et al. 2012). An outlier, NC358, rated among the most susceptible to silk colonization by A. flavus because of a high score in one of the three years, severely affected the correlation between CPA tolerance and silk resistance. Nevertheless, NC358, in addition to being the most tolerant to CPA (Fig. 7A), was among the most resistant to kernel colonization as well as AF contamination (Mideros et al. 2012).

It is of significance that the seedling assay is also predictive of resistance to AF contamination in the seed. Of the 43 lines used in the assay, 21 (Fig. 7A) have replicated field AF data reported in the literature (Bush 2008) (Fig. 7B) and the toxin content among inbreds follows a similar trend as their CPA sensitivity. The trait shows a moderate but significant correlation (Pearson $r=0.74$ with a $P$ value of $<0.0003$; and Spearman $r=0.52$ with a $P$ value of 0.023 ) with the AF data from Missouri (Fig. 7C). CPA sensitivity was also correlated with the AF data from Mideros et al. (2012), which was generated at one site but for three consecutive years. The Pearson correlation coefficient was 0.45 with a $P$ value of 0.08 (Spearman $r=0.47$, $P=0.09$ ) with all the 16 common inbreds between the two sets and 0.73 with $P=0.002$ (Spearman $r=0.7, P=0.003$ ) after removing Mo17, which accumulated the greatest amount of AF (Mideros et al. 2012) but is among the most tolerant to CPA (Fig. 7A). It is relevant to note that NRRL 3357, the isolate used in both studies (Bush 2008; Mideros et al. 2012), is a CPA producer. Taken together, these analyses showed that maize genotypes vary widely in CPA tolerance and this trait is correlated with resistance to A. flavus colonization and AF contamination. Given the spotty infection and huge variability in AF levels of even an inbred infected by the same A. flavus strain, particularly in field-grown corn (Figs. 2 and 5) or even in synthetic media, this correlation strongly suggests that the seedling root CPA sensitivity can be used as a reliable screen of maize germplasm for resistance to Aspergillus ear rot with low cost and labor inputs. Since it is a laboratory assay carried out under controlled environment, it allows a replicated screening of a large number of lines economically as well as reproducibly.

\section{Allelic variation among maize eca genes.}

Since eca genes are strongly expressed in developing seeds as well as seedling roots (Fig. 4), differences in their expression or the CPA sensitivity, or both, of ECA proteins may be an obvious, although not an exclusive, mechanism underlying the diversity in CPA tolerance among maize inbreds (Fig. 7A). It follows that single nucleotide polymorphisms (SNPs) and small insertions or deletions (indels) in the coding and regulatory sequences of eca genes may contribute to the variation in CPA tolerance. We queried the recently released beta version of the maizeGDB SNPversity database for SNPs in eca genes and $1-\mathrm{kb}$ flanking sequences on either side among NAM populations. All five eca gene models exhibit SNPs in either coding (exons), noncoding sequences, or both (Table 2 , introns and promoters). The largest number of SNPs are observed in ecal and eca2b (57 in ecal and 43 in eca2b). The other three gene models together have as few as only 13 SNPs. A majority of them are biallelic and useful for further analysis. Our current analysis is focused on the SNPs in ecal, since it is a classical maize gene with confirmed cDNA sequence and biochemical characterization of the protein (Subbaiah and Sachs 2000). Of the 57 SNPs, 50 are detected in more than one NAM inbred (and the F1 hybrid with B73 as the recurring parent), and the rest are rare, limited to one or more recombinant inbred lines (Supplementary Table S1, highlighted in yellow). Four of these are within the putative promoter $(-500 \mathrm{bp})$ of only two inbreds, HP301 and IL14H, that are moderately CPA-sensitive (Fig, 7A). To assess the effects of these SNPs on ecal expression, we compared ECA1 transcript abundance in these two lines with that of 12 other NAM inbreds differing in their CPA sensitivity (Supplementary Fig. S3). The

Table 1. Cis-regulatory elements and their positions detected in eca gene promoters (1.5 kb upstream of the putative transcription start site)

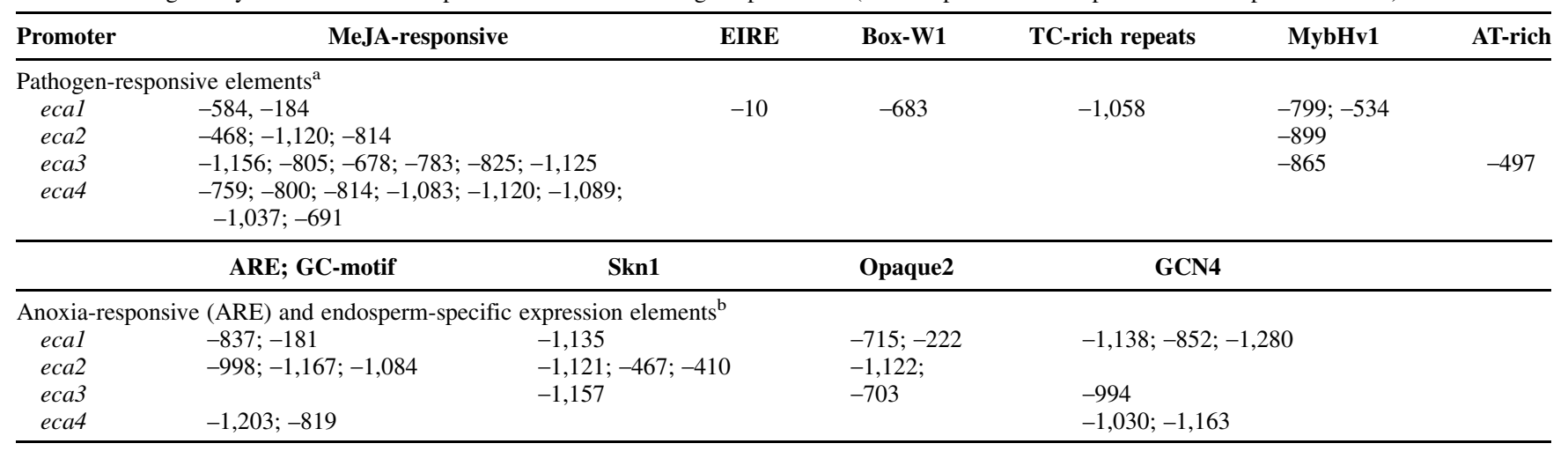

${ }^{a}$ Me-JA = methyl jasmonate-responsive; EIRE = elicitor-responsive element; Box-W1 = binding site for members of the WRKY family transcription factors; TC-rich repeats = defense and stress-responsive; MybHv1 = barely Myb1-binding domain; and AT-rich = elicitor-responsive.

b ARE and GC motif = anoxia-responsive in maize; Skn1, Opaque2, and GCCN4 = endosperm-specific expression in maize and rice. 
A
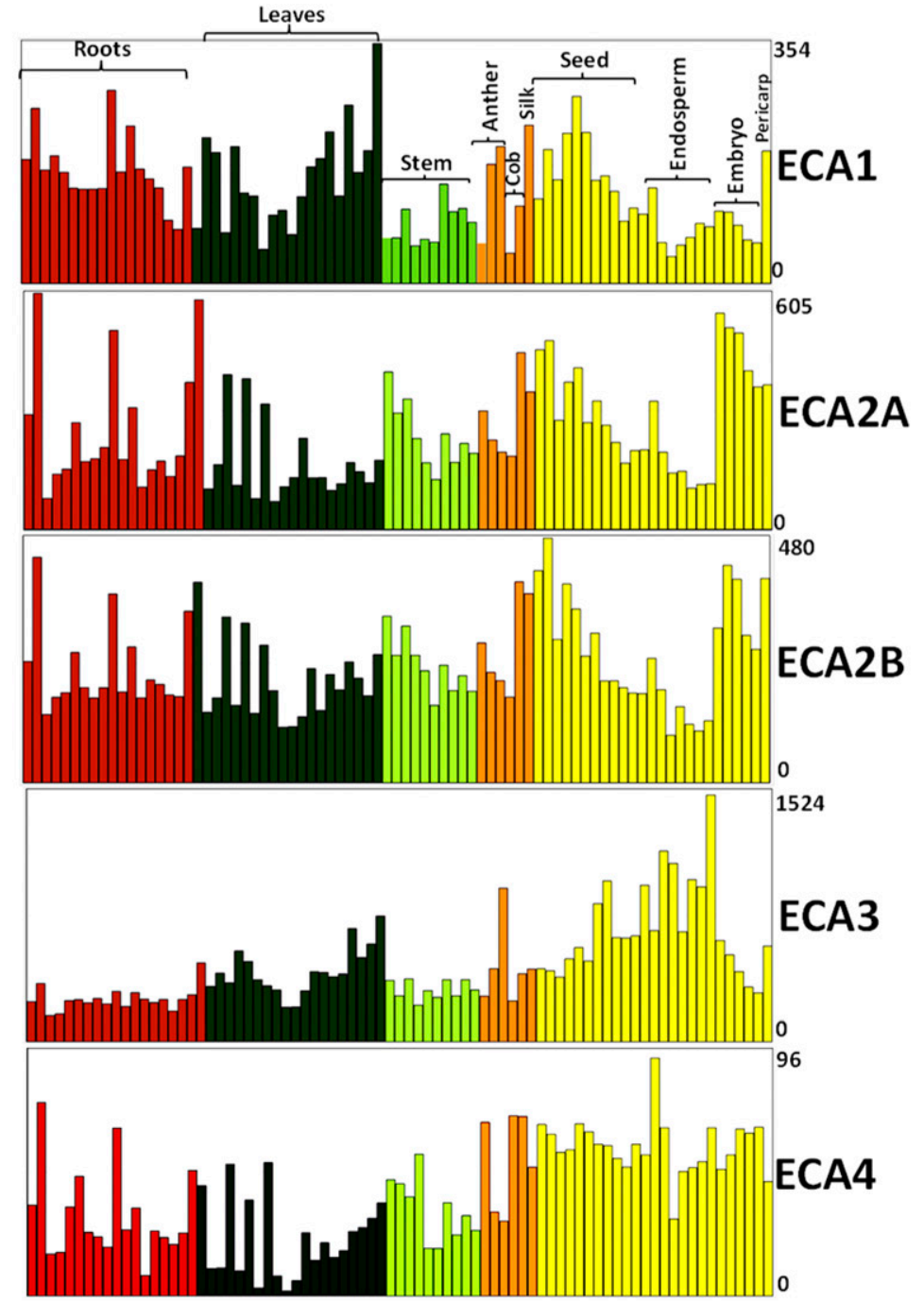

B

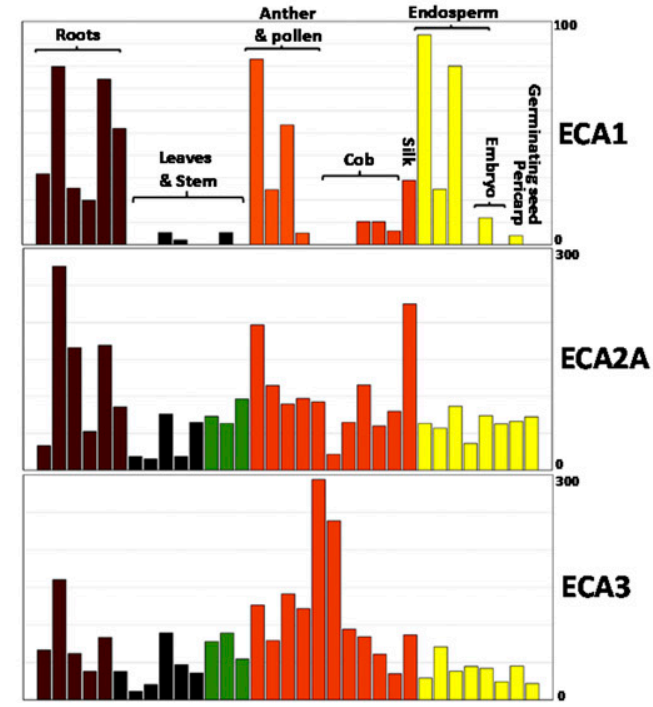

Fig. 4. A, Expression profile of eca genes during the maize life cycle. As per the guidelines for maize gene nomenclature (Maize Genetics and Genomics database [maizeGDB] nomenclature), symbols for all gene products (mRNA and proteins) are denoted in upper case nonitalicized letters. The $x$ axis shows different developmental stages from germination to seed development. Organ identities shown for the ECA1 transcript profile are common to all gene transcripts. The transcripts derived from the two gene models GRMZM2G428096 and GRMZM2G141704 for eca2 are named as endoplasmic reticulum calcium ATPase (ECA)2A and ECA2B, respectively. The scale in the $y$ axis (RNA-Seq data, in fragments per kilobase of transcript per million mapped reads) is specific to each gene. Details such as the plant age for each bar under each organ or tissue category are available at the maize GDB. B, Abundance of ECA proteins during the maize life cycle. The $x$ axis shows different developmental stages from germination to seed development. Organ identities shown for ECA1 are common to ECA2A and ECA3 proteins. No peptides corresponding to ECA2B and ECA4 were detected in tissues used in the study. The scale in the $y$ axis (spectral counts from mass spectrometry analysis) is specific to each protein isoform. The shades were modified from the original plots to make them uniform between the transcript and protein data for easy comparison. Details such as the plant age for each bar under each sample category are available at the maizeGDB database. 
average ECA1 transcript abundance in these two lines was greater than in the other 12 lines; 16 SNPs fall within introns (11 in intron 1 and five in intron 4); except for four, all 35 exonic SNPs are synonymous.

\section{DISCUSSION}

Although A. flavus is predominantly a soil-dwelling saprophyte, many isolates have evolved to be facultative pathogens on crop plants (Lillehoj 1987; Payne 1998; St. Leger et al. 2000). Even if a stringent host specificity is lacking, niche specialization or preference has often been observed among A. flavus isolates (Bayman and Cotty 1991; Mehl et al. 2012). Necrotrophs (e.g., Botrytis cinerea) often use strain-specific SMs to disrupt host cell integrity, trigger cell death, and destroy host tissue (van Kan 2006). A. flavus isolates appear to use CPA to breakdown silk resistance and gain entry into the developing ear. The evidence is as follows. Among the most abundant VCGs of Louisiana populations with a clear dichotomy of niche preference (Sweany et al. 2011), the propensity of isolates to colonize maize kernels is correlated with the ability to make much higher cytotoxic levels of CPA (Fig. 1). A. flavus seems to make far greater amounts of CPA in infected maize kernels than in synthetic media (Georgianna et al. 2010; Geiser et al. 2000). Further, CPA levels were relatively consistent within experiments, in contrast to AF levels, which vary widely even among replicate cultures (Fig. 1). Georgianna et al. (2010) tested the production of both AF and CPA under various culture conditions, such as temperature, antioxidants, nitrate, and high $\mathrm{pH}$. Unlike AF synthesis, CPA synthesis is stable or even enhanced under many conditions that are relevant to infection in the field, including high temperature. Gallic acid, the most abundant

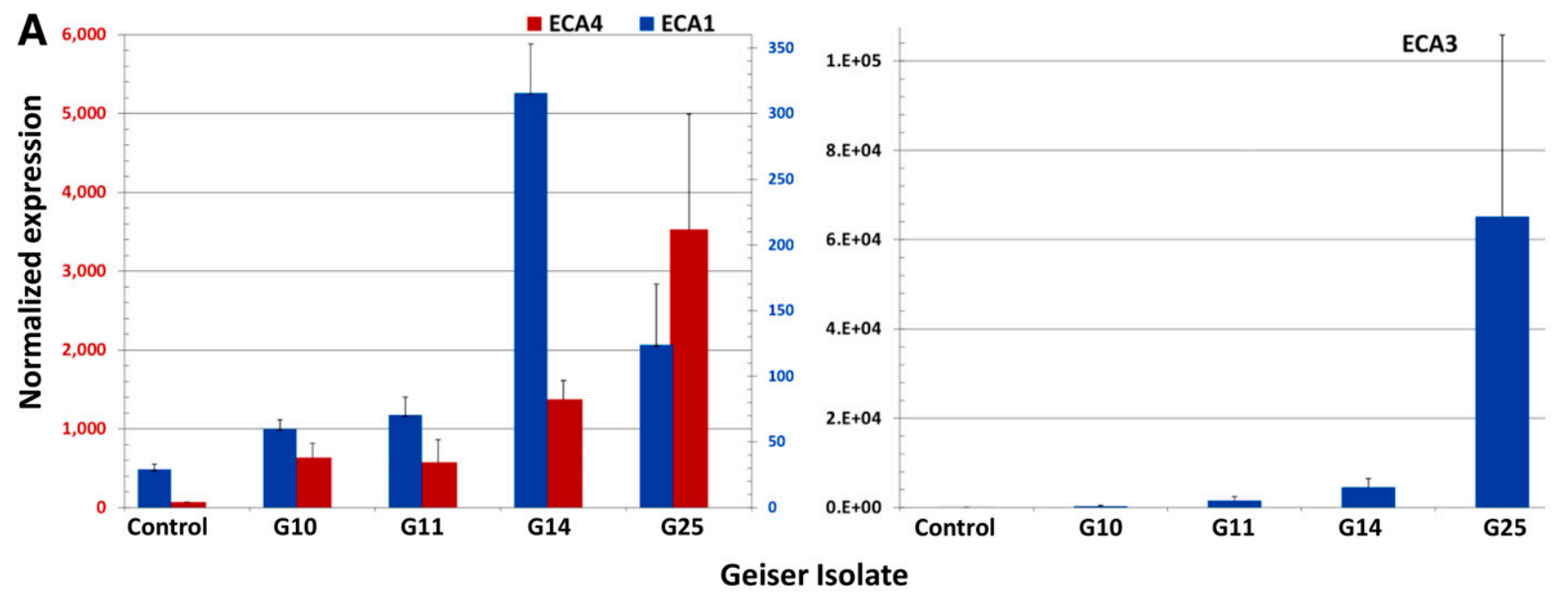

B

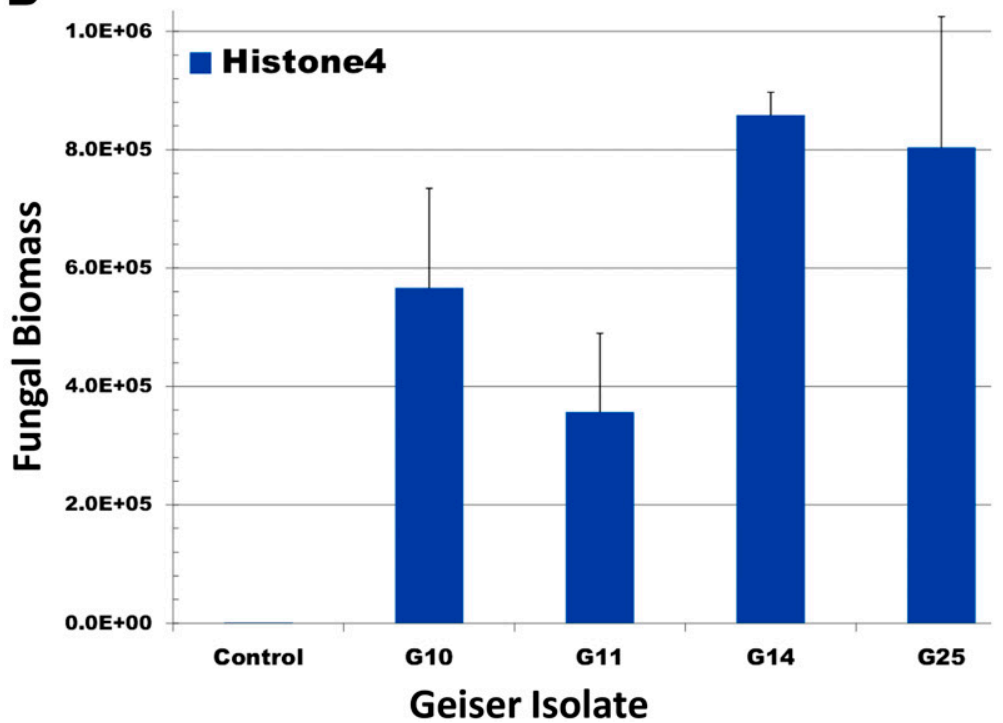

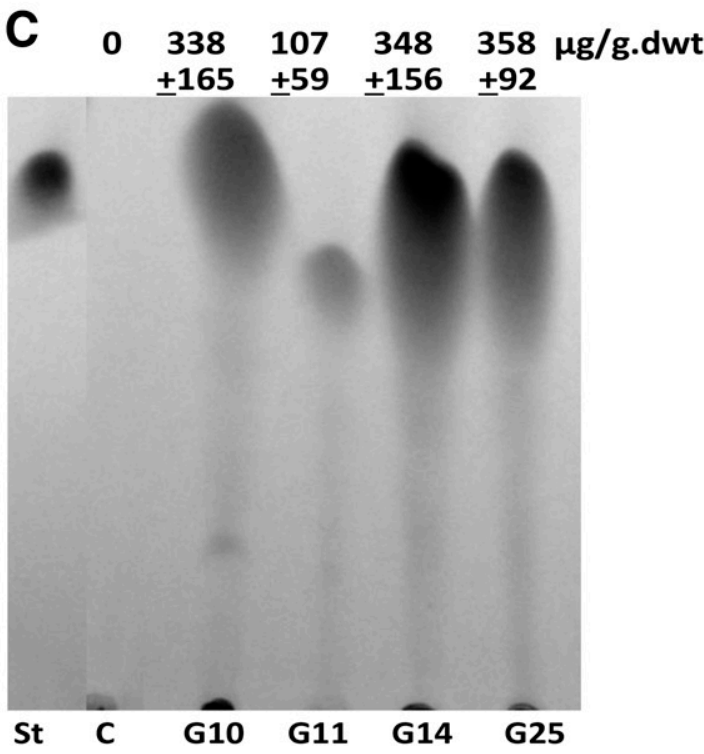

Fig. 5. A, Induction of endoplasmic reticulum calcium ATPase (ECA) transcripts in infected seeds. Blister-stage sweetcorn kernels were pin-inoculated with conidia from four Geiser isolates. Seeds, harvested after 4 days, were frozen immediately and were used for RNA extraction and reverse transcriptionquantitative polymerase chain reaction (qPCR) estimation of ECA1, ECA3, and ECA4 (shown on the right panel) transcripts. ECA2 was not included in our analyses, due to the tentative nature of the representative gene models. Data (average of three replicates +standard error [SE]) were normalized by EF1 $\alpha$ transcript copy number. Control inoculations had no conidia. B, Fungal biomass estimated as Aspergillus flavus histone4 gene copy number. DNA extracted from the same samples as in A was used for qPCR with His4 primers. Data are an average of three replicates +SE. C, Cyclopiazonic acid (CPA) levels in infected kernels. CPA was extracted from approximately $200 \mathrm{mg}$ of frozen kernel powder from the same samples as in A and was analyzed by thin-layer chromatography (TLC). Pure CPA $(12.5 \mu \mathrm{g})$ was loaded as the standard (St) in the first lane. The chloroform-extracted kernel powders were dried completely at $32^{\circ} \mathrm{C}$ for 3 days and dry mass was determined. The TLC image is representative of three replicates and the numbers shown are CPA contents in micrograms per gram of dry mass of kernel averages $\pm \mathrm{SE}$, estimated from a standard CPA curve. 
phenolic acid in maize silks, kernels, and husk leaves (Pandey et al. 2013), and a strong inhibitor of AF production has no measurable effect on CPA production (Georgianna et al. 2010; Mahoney and Molyneux 2004). The differential dynamics of $\mathrm{AF}$ and CPA production under high temperature has been shown to be regulated at the transcriptional level (O'Brian et al. 2007; Smith et al. 2008), indicating that the transcriptional regulation of these SMs in relation to isolate niche physicochemical environment (i.e., soil versus plant colonization) may be hardwired in the genome.

The most critical evidence for the role of CPA in A. flavus is from CPA-null mutants. Field evaluation of mutants for their infectivity showed that CPA nulls are significantly less effective in causing ear rot compared with their parent that can make CPA (Fig. 2). Additionally, genes encoding ECAs, the cellular targets of CPA, are most expressed in developing seeds (Fig. 4) and induced in seeds by $A$. flavus infection (Fig. 5A). The magnitude of induction is correlated with the amount of CPA made by the isolates, which, in turn, is related to isolate virulence (Fig. 5). Taken together, our studies show that CPA serves as a key pathogenicity factor in the invasion of plant cells by A. flavus while compromising the host defense response.

Comparative genomics analysis has revealed that the evolution of virulence in human pathogenic fungi is accompanied by i) gene duplication and elaboration of gene clusters encoding SMs, particularly those at the subtelomeric regions and ii) acquisition of new metabolic pathways essential for adaptation to the host environment, including its nutrient status (Moran et al. 2011). Both mechanisms seem to have played a role in the development of pathogenicity among A. flavus isolates as well. In addition to the acquisition of the CPA gene cluster (Chang et al. 2009a), our recent work suggests that the virulence of A. flavus in developing maize kernels may be related to survival under extreme hypoxia (Chalivendra et al. 2016). Further, these two mechanisms may be interrelated. For example, a comparison of CPA levels in different culture conditions suggested that
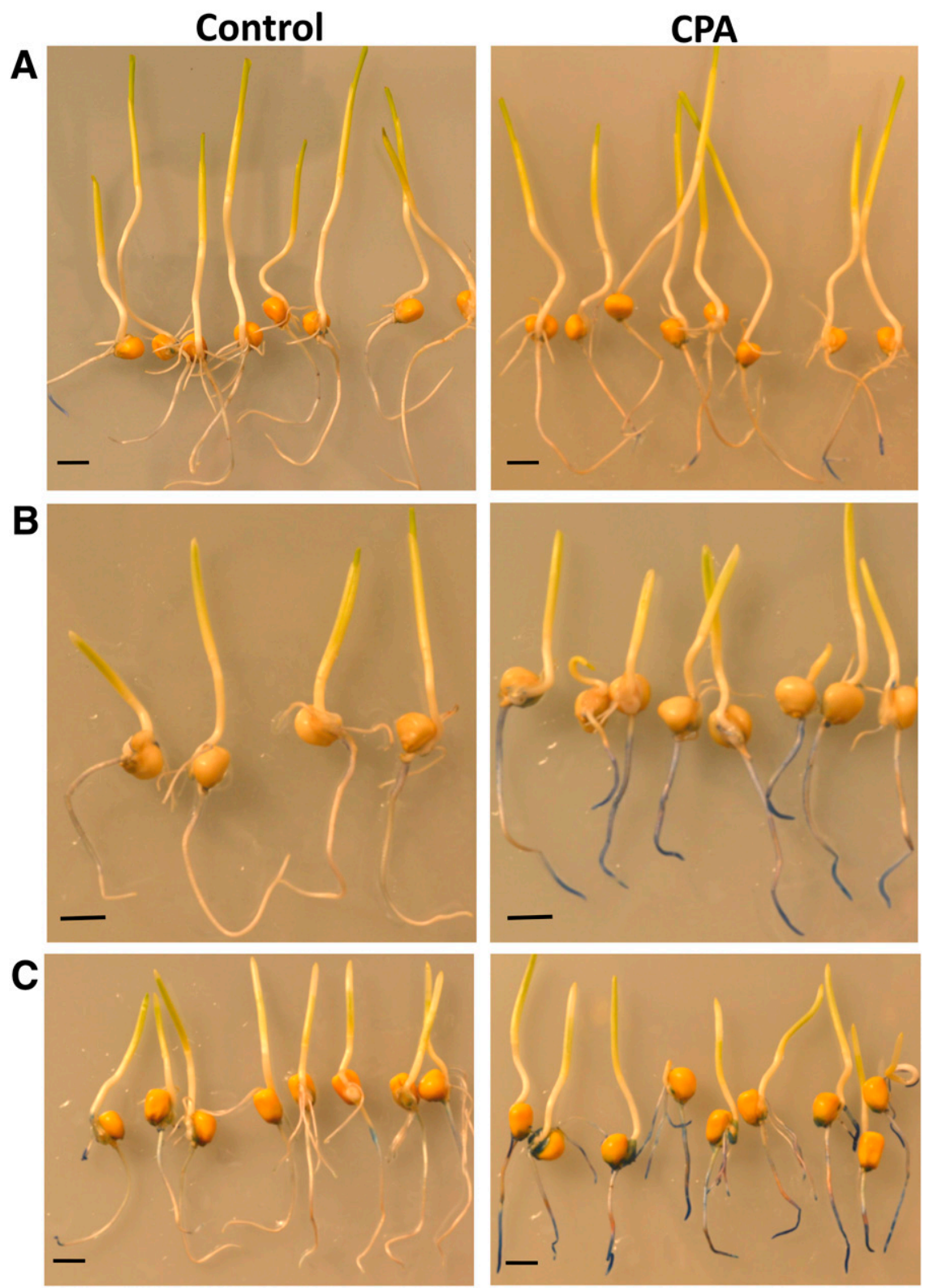

Fig. 6. Profiles of cyclopiazonic acid (CPA)-induced cell death in the primary root of maize inbreds. The extent of cell death is marked by the intensity and the length of the root stained by Evans Blue. A, The least CPA-sensitive inbreds are represented by NC358, B, moderately sensitive set by CML277, and C, the most sensitive inbreds by B73. Scale bar $=1 \mathrm{~cm}$. 
the best yields of CPA were obtained in unaerated or submerged cultures of CPA-producing Aspergillus spp. (Hermansen et al. 1984; Neethling and McGrath 1977). Similar to CPA-induced clumping of ER (Busch and Sievers 1993), oxygen depletion also induces ER aggregation into concentric circles in plant cells (Wrischer 1960). Oxygen scarcity prevalent in developing maize kernels (Chalivendra et al. 2016; Rolletschek et al. 2005) may make them more vulnerable to CPA toxicity. Further,
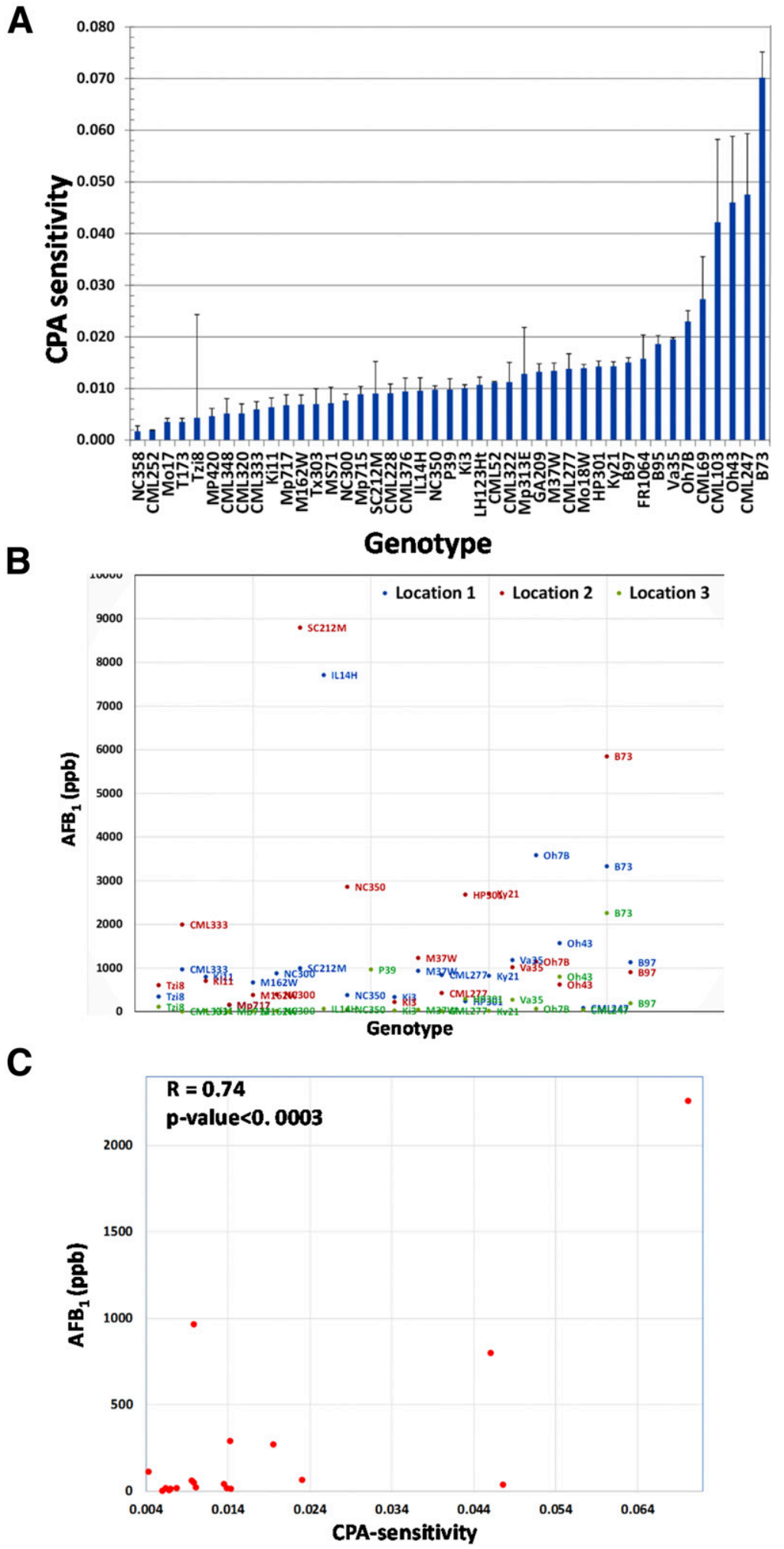

Fig. 7. A, Range of cyclopiazonic acid (CPA) sensitivity among maize inbreds. Evans Blue was extracted from a 1-cm root apex excised from destained roots and was measured spectrophotometrically as described by Chandran et al. (2008). The normalized absorbance values, a measure of cell death induced by CPA, are plotted as CPA sensitivity of indicated genotypes. B, Aflatoxin (AF) contamination levels among maize inbreds used in the CPA screen. The data plotted is extracted from a study by Bush (2008). The field study was conducted in three locations (Mississippi, Georgia, and Missouri) with $>90$ lines at each site. Although there was a general trend in genotypic susceptibility in AF accumulation, the values varied by 10 - to 100-fold within an inbred among the locations. C, Rank correlation between sensitivity to CPA and AF contamination among maize inbreds. CPA sensitivity ranking showed a significant correlation with the AF rank data from location 3 (Missouri). The relationship was not significant in the other two locations. 
ECA1 transcripts are induced only by submergence among other stress treatments tested (Subbaiah and Sachs 2000) and ecal, eca2, and eca4 promoters have conserved cis-regulatory elements essential for anaerobic inducibility (Table 1).

We successfully tested the possibility of using CPA as a surrogate for A. flavus infection to screen maize germplasm for ear rot resistance (Figs. 6 and 7). In addition to targeting a pathogenicity factor, our screen, based on primary root CPA sensitivity, has two main advantages, low inputs in terms of labor as well as the cost and high reliability enabled by a tight control of experimental (chemical treatment instead of pathogen infection) as well as environmental (laboratory instead of field) variables. The utility of our seedling screen was validated by the identification of a wide variation in CPA sensitivity among maize inbreds that include NAM parents (Figs. 6 and 7A). A comparison of inbred silk resistance and seed AF accumulation data from published field studies indicated that the seedling CPA tolerance is reflective of their resistance to fungal colonization and AF contamination (Fig. 7B and $\mathrm{C}$ ). In a previous study, postharvest resistance of maize varieties to Penicillium spp. was scored by the seed CPA content after a month-long incubation of inoculated seeds (Reddy and Reddy 1992). The inclusion of a NAM panel in the screen allows us to easily pursue the associated loci and genes for CPA tolerance and relate them to A. flavus resistance using genome-wide association studies.

Concurrent to the genome-wide approaches, we are also taking a candidate gene approach by analyzing potential effects of SNPs in eca genes on gene expression, protein function, and ultimately, on CPA tolerance in NAM populations. In addition to ECAs being the direct targets of CPA, the colocalization of three out of four eca genes to the A. flavus resistance QTL make them a rational choice for the candidate gene analysis. Sequence variations in SERCAs (eca homologs of animal cells) have significant effects on gene regulation, pump activity, and important human diseases, such as diabetes (Periasamy and Kalyanasundaram 2007; Varadi et al. 1999). In the present study, we focused on ecal encoding the only characterized ECA in maize, although SNPs are also observed in the other three genes (Table 2). Cis-regulatory variance is the major component of gene expression divergence and a key contributor to phenotypic variation among maize inbreds (Waters et al. 2017). Four SNPs in ecal are unique to the two NAM inbreds HP301 and IL14H and localized to the promoter (within $-500 \mathrm{bp}$ ). The average ECA1 transcript abundance in the roots of these two inbreds is significantly greater than that of 12 inbreds possessing the reference allele tested. Intronic variants are known to play a regulatory role in gene expression, particularly by differential splicing (Morello and Breviario 2008). Although we are yet to analyze which of the intronic SNPs are consequential, splicing variants are known to be prevalent in eca homologs both in plants and animals (Wimmers et al. 1992; Brini and Carafoli 2009), including in ecal (Subbaiah and Sachs 2000). Out of 35 exonic SNPs, 15 of them are in the 296-bp long 5' untranslated region and can potentially have posttranscriptional regulatory effects. Among 16 synonymous SNPs within the coding region, eight may have an effect on ECA1 protein levels, due to the codon usage preference, i.e., a strong bias for $\mathrm{C}$ and $\mathrm{G}$ in the

Table 2. Single nucleotide polymorphism distribution in eca genes

\begin{tabular}{lccccc}
\hline Gene ID & Total & IGR $^{\mathbf{a}}$ (promoter) & IGR $\left(\mathbf{3}^{\prime}\right)$ & Exon & Intron \\
\hline ecal & 57 & 4 & 2 & 35 & 16 \\
eca 2 & 47 & 0 & 8 & 39 & 0 \\
eca3 & 6 & 0 & 3 & 3 & 0 \\
eca4 & 3 & 3 & 0 & 0 & 0 \\
\hline
\end{tabular}

${ }^{\mathrm{a}}$ IGR $=$ inter-genomic region. degenerate third base in maize (Haberer et al. 2005; Murray et al. 1989) and, possibly, on the phenotype (Perlak et al. 1991). Among the four nonsynonymous SNPs leading to an amino acid substitution, the one in exon 8 altering an alanine to a threonine may have an effect on $\mathrm{Ca}^{2+}$ transport, based on other proteins involved in transport and secretion. For example, a similar SNP in the gene for NCKX5 altering an alanine to threonine reduces the $\mathrm{Na} / \mathrm{Ca}^{2+}$ exchange activity, resulting in lowered melanogenesis and a lighter skin color among South Asians (Wilson et al. 2013). NCKX5 is a potassium-dependent $\mathrm{Na} / \mathrm{Ca}^{2+}$ exchanger with a general function of maintaining intracellular calcium homeostasis (Stokowski et al. 2007), similar to that of ECAs. The alanine to threonine coding SNP in ECA1 protein is located close to the transmembrane 8 involved in high affinity $\mathrm{Ca}^{2+}$ binding (Clarke et al. 1989). The potential effect of the substitution on $\mathrm{Ca}^{2+}$ transport by ECA1 is yet to be determined. In the future, other candidate gene families (e.g., genes encoding the Bax inhibitor) known to interact with ECAs will also be examined.

In summary, we demonstrate that the laboratory CPA tolerance assay is a superior screen to currently used field $\mathrm{AF}$ measurements for resistance to Aspergillus ear rot. Of the two components of ear rot, i.e., fungal "colonization" and AF "contamination," CPA tolerance mechanisms can directly affect colonization by targeting CPA's killing action and, consequently, lower contamination. Field colonization measurements are fraught by high variability, cost, and labor. While laboratory kernel screening assays are cheap and robust, they report only resistance against postharvest contamination, a manageable problem, by controlling seed storage environment. On the other hand, CPA tolerance may be relevant to both preharvest and postharvest pathogenicity, since it targets the necrotrophic habit of A. flavus. Further, the trait may be simple enough to track its precise genetic basis, using GWAS and candidate gene approaches.

\section{MATERIALS AND METHODS}

\section{CPA analysis.}

CPA was extracted from six each of kernel (VCG 1, 4, 5, 7, 9, and 10) and soil (VCG 2, 3, 6, 8, 11, and 14) isolates grown in stationary cultures of $1 \mathrm{ml}$ of yeast extract sucrose medium supplemented with soytone, as described before (Chang et al. 2009b; Geiser et al. 2000), with a minor modification. To prevent oxidative degradation and tailing of the CPA, a trace amount of ascorbic acid (AA) $(100 \mu \mathrm{g} / \mathrm{ml})$ was added during extraction and TLC analysis, as recommended by Diaz et al. (2010). We also compared the CPA contents semiquantitatively, using high resolution scans of TLC plates (ChemiDoc XRS+ System; Bio-Rad) and a standard curve, developed using authentic CPA (Alomone Labs).

\section{Field testing of CPA mutants.}

A field evaluation of CPA mutants was carried out in 2015, using a sweetcorn line (cv. Miracle; La Crosse Seed) grown at the LSU Experimental Station located in Baton Rouge, LA. The middle two rows of a four-row plot were chosen for each of the A. flavus strains tested (pks-nrps and maoA mutants and their isogenic parent CA14N1). A total of 20 ears with yellowing silks ( 7 to 10 days after silk emergence) were inoculated by spraying approximately $1 \mathrm{ml}$ of a $10^{7}$ per milliliter conidial suspension to completely cover all emerged silks. Ears were harvested at maturity, were dehusked, and were dried in a hotair dryer $\left(50^{\circ} \mathrm{C}\right)$ to $<10 \%$ moisture. Seeds shelled from each ear were milled separately, and a 20-g aliquot of the seed meal was used for AF determination by high-pressure liquid chromatography. In 2016, the study was repeated with all three CPA mutants and the two parental strains, using a seed corn hybrid (25BHR26; Terral Seed). More than 100 ears per A. flavus line 
were treated, as described before, and the study was duplicated in an adjacent plot. Ears from each treatment were pooled into six replicates for AF determination. The sweet corn line and field corn hybrid used in these studies are recommended for growers in Louisiana based on their adaptability and high yield.

\section{Gene expression analysis in infected kernels.}

Developing maize seeds (cv. Golden Nuggets; a sweetcorn hybrid from Holmes Seed Company and a popular variety grown in Louisiana) at the blister stage were pin-inoculated with conidial suspensions $\left(10^{6}\right.$ per milliliter in $0.001 \%$ sodium dodecyl sulfate [SDS]) or with the carrier and no conidia. A sweet corn line was used to have assured infection and AF accumulation, facilitated by a thinner pericarp and high sucrose content of the endosperm. The study was conducted in 2014 at the LSU Experimental Station. Four isolates originally characterized by Geiser et al. (2000) were used for analysis. They were renamed as part of our group's inventory and these names are used in the manuscript for simplicity, with the original names shown in parentheses: G10 (Geiser 7-4), G11 (Geiser 11-4), G14 (Geiser 14-1), and G25 (Geiser F15). Seeds were harvested after 4 days and were immediately frozen in liquid $\mathrm{N}_{2}$, were ground to fine powder, were stored at $-70^{\circ} \mathrm{C}$, and were used in all analyses. CPA was extracted and measured as described above. RNA was extracted using TRIzol reagent, was Dnase-digested, and was purified, using silica columns (PureLink RNA mini kit; Life Technologies). Total genomic DNA was extracted using a commercial kit (Wizard Genomic DNA purification kit; Promega). Reverse transcription-quantitative polymerase chain reaction (RT-qPCR) analysis of fungal and maize steady state transcript levels was carried out using $5 \mathrm{ng}$ of total RNA and specific primers for each gene (Supplementary Table $\mathrm{S} 2$ ), in a single-tube reaction (Quanta Biosciences). To confirm the absence of genomic DNA contamination, no-RT controls were included for all RNA samples. The amplification of the constitutively expressed A. flavus histone $\mathrm{H} 4$ (His4) and maize elongation factor $1 \alpha$ genes were used for the copy number estimation, using DNA as the template and, for normalizing RT-qPCR data, using RNA as the template.

\section{CPA tolerance screen.}

CPA sensitivity among maize inbreds was measured as the intensity of cell death by exposing the roots of 3- or 4-day-old seedlings (when the radicle is 3 to $4 \mathrm{~cm}$ long) to $15 \mathrm{ml}$ of $20 \mu \mathrm{M}$ $\mathrm{CPA}$ for approximately $18 \mathrm{~h}$ at $28^{\circ} \mathrm{C}$. After initial testing of a range of concentrations (10 to $100 \mu \mathrm{M})$ on a few inbreds of known A. flavus resistance, $20 \mu \mathrm{M} \mathrm{CPA}$, which gave a dynamic range of cell death (Fig. 5), was chosen for the actual screen. The control had dimethyl sulfoxide (the solvent used in CPA stock) in addition to $0.1 \mathrm{mg}$ of AA per milliliter, to prevent oxidation of CPA. By $12 \mathrm{~h}$, there was visible cell death in many inbreds, as indicated by root browning in the CPA set. This was confirmed by staining the roots with Evans Blue according to Chandran et al. (2008). Although staining intensity differed among the lines immediately after destaining in $0.1 \mathrm{mM} \mathrm{CaCl}_{2}$, the differences became prominent and measurable after $24 \mathrm{~h}$ of recovery in destaining solution. Evans Blue was extracted from root tips ( 1 to $1.5 \mathrm{~cm}$ from the apex) by macerating them in $1 \%$ SDS and reading the clarified extracts at $600 \mathrm{~nm}$. Normalized absorbance, i.e., $\left(\mathrm{A}_{600} /\right.$ root tip in treated $)-\left(\mathrm{A}_{600} /\right.$ root tip in the control from the same inbred), was directly used for plotting the inbred CPA sensitivity. Broad sense heritability was calculated as the proportion of phenotypic variation due to genetic factors $\left(\mathrm{V}_{\mathrm{g}}\right)$ from the total variance $\left(\mathrm{V}_{\mathrm{g}}+\mathrm{V}_{\mathrm{e}}\right)$. $\mathrm{V}_{\mathrm{g}}$ is between the genotype variance component and $\mathrm{V}_{\mathrm{e}}$ is the within residual (error) variance derived from the analysis of variance of the screen data (Falconer and Mackay 1996).

\section{SNP analysis.}

The recently released beta version of SNPversity was queried for SNP profiles in eca genes. The database is developed using AGPv2 version of B73 reference genome.

\section{ACKNOWLEDGMENTS}

S. Chalivendra and K. Damann thank AMCOE (Aflatoxin Mitigation Center of Excellence) for the funding support through the National Corn Growers Association. The authors also thank many cooperators who shared seed stocks, particularly D. Wilson (Valent BioSciences), R. Nelson (Cornell University), P. Balint-Kurti (United States Department of AgricultureAgricultural Research Service [USDA-ARS], Raleigh), and P. Williams (USDA-ARS, Stoneville). S. Chalivendra thanks R. Nelson for suggestions during the conceptualization of the project and D. Schott (maizeGDB) for help with SNPversity. We thank the anonymous reviewers for greatly improving our manuscript with their comments and suggestions.

\section{LITERATURE CITED}

Amaike, S., and Keller, N. P. 2009. Distinct roles for VeA and LaeA in development and pathogenesis of Aspergillus flavus. Eukaryot. Cell 8: 1051-1060.

AMCOE. 2013. Aflatoxins: Potential health threat to humans and animals. Aflatoxin Mitigation Center of Excellence, Texas Corn Producers, Lubbock, TX, U.S.A.

Bayman, P., and Cotty, P. J. 1991. Vegetative compatibility and genetic diversity in the Aspergillus flavus population of a single field. Can. J. Bot. 69:1707-1711.

Benkhemmar, O., Gaudemer, F., and Bouvier-Fourcade, I. 1985. Heterokaryosis between Aspergillus oryzae cyclopiazonic acid-defective strains: Method for estimating the risk of inducing toxin production among cyclopiazonic acid-defective industrial strains. Appl. Environ. Microbiol. 50:1087-1093.

Berridge, M. J. 1993. Inositol trisphosphate and calcium signalling. Nature 361:315-325.

Bok, J. W., and Keller, N. P. 2016. Insight into fungal secondary metabolism from ten years of LaeA research. Pages 21-29 in: Biochemistry and Molecular Biology, Vol. III. D. Hoffmeister, ed. Springer International Publishing, Gewerbestrasse, Switzerland.

Brini, M., and Carafoli, E. 2009. Calcium pumps in health and disease. Physiol. Rev. 89:1341-1378.

Busch, M. B., and Sievers, A. 1993. Membrane traffic from the endoplasmic reticulum to the Golgi apparatus is disturbed by an inhibitor of the $\mathrm{Ca}^{2+}$-ATPase in the ER. Protoplasma 177:23-31.

Bush, D. 2008. The role of genetic and phenotypic diversity in maize and its effects on aflatoxin accumulation by the fungus Aspergillus flavus. Ph.D. thesis. University of Missouri, Columbia, MO, U.S.A. http://hdl. handle.net/10355/6633

Campbell, K. W., and White, D. G. 1995. Evaluation of corn genotypes for resistance to Aspergillus ear rot, kernel infection, and aflatoxin production. Plant Dis. 79:1039-1045.

Chalivendra, S., DeRobertis, C., and Damann, K. 2016. Hypoxia tolerance as a factor in Aspergillus flavus invasion and toxin contamination of developing maize seeds. APS Annual Meeting, July 3-August 3, 2016 , Tampa, Florida. American Phytopathological Society, St. Paul, MN, U.S.A.

Chandran, D., Sharopova, N., VandenBosch, K. A., Garvin, D. F., and Samac, D. A. 2008. Physiological and molecular characterization of aluminum resistance in Medicago truncatula. BMC Plant Biol. 8:89.

Chang, P.-K., Ehrlich, K. C., and Fujii, I. 2009a. Cyclopiazonic acid biosynthesis of Aspergillus flavus and Aspergillus oryzae. Toxins (Basel) 1:74-99.

Chang, P.-K., Horn, B. W., and Dorner, J. W. 2009b. Clustered genes involved in cyclopiazonic acid production are next to the aflatoxin biosynthesis gene cluster in Aspergillus flavus. Fungal Genet. Biol. 46:176-182.

Clarke, D. M., Loo, T. W., Inesi, G., and MacLennan, D. H. 1989. Location of high affinity $\mathrm{Ca}^{2+}$-binding sites within the predicted transmembrane domain of the sarcoplasmic reticulum $\mathrm{Ca}^{2+}$-ATPase. Nature 339:476478.

Damann, K. E. 2015. Atoxigenic Aspergillus flavus biological control of aflatoxin contamination: What is the mechanism? World Mycotoxin J. 8:235-244.

Dashek, W. V., Harman, R. L., Adlestein, L. B., Morton, W. A., Rapisarda, B. M., Chancey, J. C., and Llewellyn, G. C. 1981. Use of Lilium longiflorum, cv. ace pollen germination and tube elongation as a bioassay for the hepatocarcinogens, aflatoxins. Environ. Health Perspect. 40:267-278. 
Diaz, G. J., Thompson, W., and Martos, P. A. 2010. Stability of cyclopiazonic acid in solution. World Mycotoxin J. 3:25-33.

Dolezal, A. L., Obrian, G. R., Nielsen, D. M., Woloshuk, C. P., Boston, R. S., and Payne, G. A. 2013. Localization, morphology and transcriptional profile of Aspergillus flavus during seed colonization. Mol. Plant Pathol. 14:898-909.

Dorner, J. W., Cole, R. J., and Diener, U. L. 1984. The relationship of Aspergillus flavus and Aspergillus parasiticus with reference to production of aflatoxins and cyclopiazonic acid. Mycopathologia 87: 13-15.

Duran, R. M., Cary, J. W., and Calvo, A. M. 2007. Production of cyclopiazonic acid, aflatrem, and aflatoxin by Aspergillus flavus is regulated by $v e A$, a gene necessary for sclerotial formation. Appl. Microbiol. Biotechnol. 73:1158-1168.

Duran, R. M., Cary, J. W., and Calvo, A. M. 2009. The role of veA in Aspergillus flavus infection of peanut, corn and cotton. Open Mycol. J. 3:27-36.

Edgar, R. C. 2004. MUSCLE: Multiple sequence alignment with high accuracy and high throughput. Nucleic Acids Res. 32:1792-1797.

Ehrlich, K., Wei, Q., Brown, R. L., and Bhatnagar, D. 2011. Inverse correlation of ability to produce aflatoxin and Aspergillus colonization of maize seed. Food Nutr. Sci. 2:486-489.

Falconer, D. S., and Mackay, T. F. C. 1996. Introduction to Quantitative Genetics, 4th ed. Longman Group Ltd., London.

Geiser, D. M., Dorner, J. W., Horn, B. W., and Taylor, J. W. 2000. The phylogenetics of mycotoxin and sclerotium production in Aspergillus flavus and Aspergillus oryzae. Fungal Genet. Biol. 31:169-179.

Georgianna, D. R., Fedorova, N. D., Burroughs, J. L., Dolezal, A. L., Bok, J. W., Horowitz-Brown, S., Woloshuk, C. P., Yu, J., Keller, N. P., and Payne, G. A. 2010. Beyond aflatoxin: Four distinct expression patterns and functional roles associated with Aspergillus flavus secondary metabolism gene clusters. Mol. Plant Pathol. 11:213-226.

Goeger, D. E., Riley, R. T., Dorner, J. W., and Cole, R. J. 1988 Cyclopiazonic acid inhibition of the $\mathrm{Ca}^{2+}$-transport ATPase in rat skeletal muscle sarcoplasmic reticulum vesicles. Biochem. Pharmacol. 37:978-981.

Haberer, G., Young, S., Bharti, A. K., Gundlach, H., Raymond, C., Fuks, G., Butler, E., Wing, R. A., Rounsley, S., Birren, B., Nusbaum, C., Mayer, K. F., and Messing, J. 2005. Structure and architecture of the maize genome. Plant Physiol. 139:1612-1624.

Henry, W. B., Williams, W. P., Windham, G. L., and Hawkins, L. K. 2009. Evaluation of maize inbred lines for resistance to Aspergillus and Fusarium ear rot and mycotoxin accumulation. Agron. J. 101:1219-1226.

Hermansen, K., Frisvad, J. C., Emborg, C., and Hansen, J. 1984. Cyclopiazonic acid production by submerged cultures of Penicillium and Aspergillus strains. FEMS Microbiol. Lett. 21:253-261.

Hong, E. J., Kim, N. K., Lee, D., Kim, W. G., and Lee, I. 2015. Overexpression of the laeA gene leads to increased production of cyclopiazonic acid in Aspergillus fumisynnematus. Fungal Biol. 119: 973-983.

Horn, B. W., Greene, R. L., and Dorner, J. W. 1995. Effect of corn and peanut cultivation on soil populations of Aspergillus flavus and A. parasiticus in southwestern Georgia. Appl. Environ. Microbiol. 61: 2472-2475.

Hruska, Z., Rajasekaran, K., Yao, H., Kincaid, R., Darlington, D., Brown, R. L., Bhatnagar, D., and Cleveland, T. E. 2014. Co-inoculation of aflatoxigenic and non-aflatoxigenic strains of Aspergillus flavus to study fungal invasion, colonization, and competition in maize kernels. Front. Microbiol. 5:122.

Ihara-Ohori, Y., Nagano, M., Muto, S., Uchimiya, H., and Kawai-Yamada, M. 2007. Cell death suppressor Arabidopsis bax inhibitor-1 is associated with calmodulin binding and ion homeostasis. Plant Physiol. 143: 650-660.

Ishikawa, T., Watanabe, N., Nagano, M., Kawai-Yamada, M., and Lam, E. 2011. Bax inhibitor-1: A highly conserved endoplasmic reticulumresident cell death suppressor. Cell Death Differ. 18:1271-1278.

Iwano, M., Entani, T., Shiba, H., Kakita, M., Nagai, T., Mizuno, H., Miyawaki, A., Shoji, T., Kubo, K., Isogai, A., and Takayama, S. 2009. Fine-tuning of the cytoplasmic $\mathrm{Ca}^{2+}$ concentration is essential for pollen tube growth. Plant Physiol. 150:1322-1334.

Johnson, N. A., Liu, F., Weeks, P. D., Hentzen, A. E., Kruse, H. P., Parker, J. J., Laursen, M., Nissen, P., Costa, C. J., and Gatto, C. 2009. A tomato ER-type $\mathrm{Ca}^{2+}$-ATPase, LCA1, has a low thapsigargin-sensitivity and can transport manganese. Arch. Biochem. Biophys. 481:157-168.

Kale, S. P., Milde, L., Trapp, M. K., Frisvad, J. C., Keller, N. P., and Bok, J. W. 2008. Requirement of LaeA for secondary metabolism and sclerotial production in Aspergillus flavus. Fungal Genet. Biol. 45: 1422-1429.
Klich, M. A., and Pitt, J. L. 1988. Differentiation of Aspergillus flavus from A. parasiticus and other closely related species. Trans. Br. Mycol. Soc. 91:99-108.

Lanubile, A., Ferrarini, A., Maschietto, V., Delledonne, M., Marocco, A., and Bellin, D. 2014. Functional genomic analysis of constitutive and inducible defense responses to Fusarium verticillioides infection in maize genotypes with contrasting ear rot resistance. BMC Genomics 15:710.

Li, C., Gloer, J. B., Wicklow, D. T., and Dowd, P. F. 2002. Thiersinines A and B: Novel antiinsectan indole diterpenoids from a new fungicolous Penicillium species (NRRL 28147). Org. Lett. 4:3095-3098.

Li, X., Chanroj, S., Wu, Z., Romanowsky, S. M., Harper, J. F., and Sze, H. 2008. A distinct endosomal $\mathrm{Ca}^{2+} / \mathrm{Mn}^{2+}$ pump affects root growth through the secretory process. Plant Physiol. 147:1675-1689.

Liang, F., and Sze, H. 1998. A high-affinity Ca2+ pump, ECA1, from the endoplasmic reticulum is inhibited by cyclopiazonic acid but not by thapsigargin. Plant Physiol. 118:817-825.

Lillehoj, E. B. 1987. The aflatoxin-in-maize problem: The historical perspective. Pages 13-32 in: Aflatoxin in Maize: A Proceedings of the Workshop. M. S. Zuber, E. B. Lillehoj, and B. L. Renfro, eds. CIMMYT (International Maize and Wheat Improvement Center), El Batan, Mexico.

Liu, X., and Walsh, C. T. 2009. Characterization of cyclo-acetoacetyl-Ltryptophan dimethylallyltransferase in cyclopiazonic acid biosynthesis: Substrate promiscuity and site directed mutagenesis studies. Biochemistry 48:11032-11044.

Mahoney, N., and Molyneux, R. J. 2004. Phytochemical inhibition of aflatoxigenicity in Aspergillus flavus by constituents of walnut (Juglans regia). J. Agric. Food Chem. 52:1882-1889.

Matsumura, H., Nirasawa, S., Kiba, A., Urasaki, N., Saitoh, H., Ito, M., Kawai-Yamada, M., Uchimiya, H., and Terauchi, R. 2003. Overexpression of Bax inhibitor suppresses the fungal elicitor-induced cell death in rice (Oryza sativa L) cells. Plant J. 33:425-434.

Mehl, H. L., Jaime, R., Callicott, K. A., Probst, C., Garber, N. P., OrtegaBeltran, A., Grubisha, L. C., and Cotty, P. J. 2012. Aspergillus flavus diversity on crops and in the environment can be exploited to reduce aflatoxin exposure and improve health. Ann. N. Y. Acad. Sci. 1273: 7-17.

Mideros, S. X., Warburton, M. L., Jamann, T. M., Windham, G. L., Williams, W. P. and Nelson, R. J. 2014. Quantitative trait loci for resistance to Aspergillus ear rot: Analysis by linkage mapping, characterization of near-isogenic lines and meta-analysis. Crop Sci. 54:127-142.

Mideros, S. X., Windham, G. L., Williams, W. P., and Nelson, R. J. 2012. Tissue-specific components of resistance to Aspergillus ear rot of maize. Phytopathology 102:787-793.

Möller, S., Croning, M. D. R., and Apweiler, R. 2001. Evaluation of methods for the prediction of membrane spanning regions. Bioinformatics 17:646-653

Moran, G. P., Coleman, D. C., and Sullivan, D. J. 2011. Comparative genomics and the evolution of pathogenicity in human pathogenic fungi Eukaryot. Cell 10:34-42.

Morello, L., and Breviario, D. 2008. Plant spliceosomal introns: Not only cut and paste. Curr. Genomics 9:227-238.

Murray, E. E., Lotzer, J., and Eberle, M. 1989. Codon usage in plant genes. Nucleic Acids Res. 17:477-498.

Neethling, D. C., and McGrath, R. M. 1977. Metabolic development and mitochondrial changes during cyclopiazonic acid production in Penicillium cyclopium. Can. J. Microbiol. 23:856-872.

Nemchinov, L. G., Shabala, L., and Shabala, S. 2008. Calcium efflux as a component of the hypersensitive response of Nicotiana benthamiana to Pseudomonas syringae. Plant Cell Physiol. 49:40-46.

O’Brian, G. R., Georgianna, D. R., Wilkinson, J. R., Yu, J., Abbas, H. K., Bhatnagar, D., Cleveland, T. E., Nierman, W., and Payne, G. A. 2007. The effect of elevated temperature on gene transcription and aflatoxin biosynthesis. Mycologia 99:232-239.

Pandey, R., Singh, A., Maurya, S., Singh, U. P., and Singh, M. 2013. Phenolic acids in different preparations of Maize (Zea mays) and their role in human health. Int. J. Curr. Microbiol. App. Sci. 2:84-92.

Payne, G. A. 1998. Process of contamination by aflatoxin-producing fungi and their impact on crops. Pages 279-306 in: Mycotoxins in agriculture and food safety. Sinha, K. K., and Bhatnager, D., eds. Marcel Dekker, New York.

Periasamy, M., and Kalyanasundaram, A. 2007. SERCA pump isoforms: Their role in calcium transport and disease. Muscle Nerve 35:430-442.

Perlak, F. J., Fuchs, R. L., Dean, D. A., McPherson, S. L., and Fischhoff, D. A. 1991. Modification of the coding sequence enhances plant expression of insect control protein genes. Proc. Natl. Acad. Sci. U.S.A 88:3324-3328. 
Qudeimat, E., Faltusz, A. M. C., Wheeler, G., Lang, D., Holtorf, H. Brownlee, C., Reski, R., and Frank, W. 2008. A PIIB-type $\mathrm{Ca}^{2+}$-ATPase is essential for stress adaptation in Physcomitrella patens. Proc. Natl. Acad. Sci. U.S.A. 105:19555-19560.

Reddy, V. K., and Reddy, S. M. 1992. Cyclopiazonic acid production by Penicillium griseofulvum in relation to different cultivars of maize. World J. Microbiol. Biotechnol. 8:208-209.

Reverberi, M., Punelli, M., Scala, V., Scarpari, M., Uva, P., Mentzen, W. I. et al. 2013. Genotypic and phenotypic versatility of Aspergillus flavus during maize exploitation. PLoS ONE 7:e68735.3.

Rolletschek, H., Koch, K., Wobus, U., and Borisjuk, L. 2005. Positional cues for the starch/lipid balance in maize kernels and resource partitioning to the embryo. Plant J. 42:69-83.

Sekhon, R. S., Childs, K. L., Santoro, N., Foster, C. E., Buell, C. R., de Leon, N., and Kaeppler, S. M. 2012. Transcriptional and metabolic analysis of senescence induced by preventing pollination in maize. Plant Physiol. 159:1730-1744.

Sekhon, R. S., Lin, H., Childs, K. L., Hansey, C. N., Buell, C. R., de Leon, N., and Kaeppler, S. M. 2011. Genome-wide atlas of transcription during maize development. Plant J. 66:553-563.

Smith, C. A., Robertson, D., Yates, B., Nielsen, D. M., Brown, D., Dean, R. A., and Payne, G. A. 2008. The effect of temperature on natural antisense transcript (NAT) expression in Aspergillus flavus. Curr. Genet. 54:241-269.

St. Leger, R. J., Screen, S. E., and Shams-Pirzadeh, B. 2000. Lack of host specialization in Aspergillus flavus. Appl. Environ. Microbiol. 66:320-324.

Stelpflug, S. C., Sekhon, R. S., Vaillancourt, B., Hirsch, C. N., Buell, C. R., de Leon, N., and Kaeppler, S. M. 2016. An expanded maize gene expression atlas based on RNA-sequencing and its use to explore root development. Plant Genome 9. doi:10.3835/plantgenome2015.04.0025. Published online.

Stokowski, R. P., Pant, P. V., Dadd, T., Fereday, A., Hinds, D. A., Jarman, C., Filsell, W., Ginger, R. S., Green, M. R., van der Ouderaa, F. J., and Cox, D. R. 2007. A genomewide association study of skin pigmentation in a South Asian population. Am. J. Hum. Genet. 81:1119-1132.

Subbaiah, C. C., and Sachs, M. M. 2000. Maize capl encodes a novel SERCA-type calcium-ATPase with a calmodulin-binding domain. J. Biol. Chem. 275:21678-21687.

Sweany, R. R., Damann, K. E., Jr., and Kaller, M. D. 2011. Comparison of soil and corn kernel Aspergillus flavus populations: Evidence for niche specialization. Phytopathology 101:952-959.

TePaske, M. R., Gloer, J. B., Dowd, P. F., and Wicklow, D. T. 1992. Aflavarin and $\beta$-aflatrem: New antiinsectan metabolites from the sclerotia of Aspergillus flavus. J. Nat. Prod. 55:1080-1086.

TePaske, M. R., Gloer, J. B., Wicklow, D. T., and Dowd, P. F. 1989. Three new aflavinines from the sclerotia of Aspergillus tubingensis. Tetrahedron 45:4961-4968

van Kan, J. A. L. 2006. Licensed to kill: The lifestyle of a necrotrophic plant pathogen. Trends Plant Sci. 11:247-253.

Varadi, A., Lebel, L., Hashim, Y., Mehta, Z., Ashcroft, S. J. H., and Turner, R. 1999. Sequence variants of the sarco(endo)plasmic reticulum $\mathrm{Ca}^{2+}$ )transport ATPase 3 gene (SERCA3) in Caucasian type II diabetic patients (UK Prospective Diabetes Study 48). Diabetologia 42:1240-1243.

Walley, J. W., Sartor, R. C., Shen, Z., Schmitz, R. J., Wu, K. J., Urich, M. A., Nery, J. R., Smith, L. G., Schnable, J. C., Ecker, J. R., and Briggs, S. P.
2016. Integration of omic networks in a developmental atlas of maize. Science 353:814-818.

Walley, J. W., Shen, Z., Sartor, R., Wu, K. J., Osborn, J., Smith, L. G., and Briggs, S. P. 2013. Reconstruction of protein networks from an atlas of maize seed proteotypes. Proc. Natl. Acad. Sci. U.S.A. 110:E4808-E4817.

Warburton, M. L., and Williams, W. P. 2014. Aflatoxin resistance in maize: What have we learned lately? Adv. Bot. 2014:352831.

Warburton, M. L., Tang, J. D., Windham, G. L., Hawkins, L. K., Murray, S. C., Xu, W., Boykin, D., Perkins, A., and Williams, W. P. 2015. Genome-wide association mapping of Aspergillus flavus and aflatoxin accumulation resistance in maize. Crop Sci. 55:1857-1867.

Waters, A., Makarevitch, I., Noshay, J., Burghardt, L., Hirsch, C. N., Hirsch, C. D., and Springer, N. 2017. Natural variation for gene expression responses to abiotic stress in maize. Plant J. 89:706-717.

Wicklow, D. T., Dowd, P. F., and Gloer, J. B. 1994. Antiinsectan effects of Aspergillus metabolites. Pages 93-114 in: The genus Aspergilllus. K. A. Powell, A. Renwick, and J. F. Peberdy, eds. Plenum Press, New York.

Willcox, M. C., Davis, G. L., Warburton, M. L., Windham, G. L., Abbas, H. K., Betrán, J., Holland, J. B., and Williams, W. P. 2013. Confirming quantitative trait loci for aflatoxin resistance from $\mathrm{Mp} 313 \mathrm{E}$ in different genetic backgrounds. Mol. Breed. 32:15-26.

Wilson, M., Ginger, R. S., Dadd, T., Gunn, D., Lim, F.-L., Sawicka, M., Sandel, M., Schnetkamp, P. P. M., and Green, M. R. 2013. NCKX5, a natural regulator of human skin colour variation, regulates the expression of key pigment genes MC1R and AlphaMSH and alters cholesterol homeostasis in normal human melanocytes. Sodium Calcium Exchange: A Growing Spectrum of Pathophysiological Implications, Advances in Experimental Medicine and Biology, Vol. 961. L. Annunziato, ed. Springer Science, New York.

Wimmers, L. E., Ewing, N. N., and Bennett, A. B. 1992. Higher plant $\mathrm{Ca}^{2+}$ ATPase: Primary structure and regulation of mRNA abundance by salt. Proc. Natl. Acad. Sci. U.S.A. 89:9205-9209.

Wrischer, M. 1960. Ver/inderungen des endoplasmatischen Reticuhims pflanzlicher Zellen, verursacht durch Sauerstoffmangel. Naturwissenschaften 47:521-522.

Yamamoto, Y., Kobayashi, Y., and Matsumoto, H. 2001. Lipid peroxidation is an early symptom triggered by aluminum, but not the primary cause of elongation inhibition in pea roots. Plant Physiol. 125:199-208.

Yang, K., Liang, L., Ran, F., Liu, Y., Li, Z., Lan, H., Gao, P., Zhuang, Z., Zhang, F., Nie, X., Kalayu Yirga, S., and Wang, S. 2016. The DmtA methyltransferase contributes to Aspergillus flavus conidiation, sclerotia production, aflatoxin biosynthesis and virulence. Sci. Rep. 6:23259.

Zhu, X., Caplan, J., Mamillapalli, P., Czymmek, K., and Dinesh-Kumar, S. P. 2010. Function of endoplasmic reticulum calcium ATPase in innate immunity-mediated programmed cell death. EMBO J. 29:1007-1018.

Zuppini, A., Navazio, L., and Mariani, P. 2004. Endoplasmic reticulum stress-induced programmed cell death in soybean cells. J. Cell Sci. 117: 2591-2598.

\section{AUTHOR-RECOMMENDED INTERNET RESOURCES}

Maize Genetics and Genomics database (maizeGDB): www.maizegdb.org maizeGDB SNPversity: http://www.maizegdb.org/snpversity maizeGDB nomenclature: http://www.maizegdb.org/nomenclature 